\title{
A Comparative Study of Some Physiological Variables between People with Obesity and Non-obesity
}

\author{
Atheer Abbas Mustafa ${ }^{1}$, Ahmed Abdulameer Ahmed ${ }^{1}$ \\ ${ }^{1}$ Asst. Prof., Dept. of Students Activities/University of Basra-Iraq
}

\begin{abstract}
The tremendous technological progress that led to the dependence of individuals on the machine in the modern age and in all different fields led to the lack of human movement and thus the lack of its physical and physiological efficacy, which made it vulnerable to infection with many diseases, which are called diseases of lack of movement The ideal body weight is a vital subject for the human being during the stages of his life and the development of his maturity. As well as, it is one of the necessary indicators to follow the health, functional and psychological state in which researchers and specialists work in the medical, sports and psychological fields. The importance of study is to have aknowledge regarding the physiological variables of obese and non-obese people and making comparisons between them to understand the positive effects of the ideal weight of individuals, which is reached through the practice of physical activity and constantly on the physiological variables and work to develop and improve these variables in a way that serves the health aspect. The researchers used the descriptive method in the survey. It is the best approach in achieving the study goals. The study sample was chosen in an intentional way. It was represented by the students of the third stage of the College of Physical Education at the University of Basra, where the sample size reached (30) students from the College of Physical Education and Sports Science. It was divided into two groups, and the size of each group was (15) participants, after excluding the female students who were (5). Dividing the sample into two groups, one that suffers from an increase in weight and another of normal weight according to the body mass index, measuring blood pressure, the number of heartbeat and measuring some physiological variables. The researchers concluded that people without obesity are healthier and more active than infected people who suffer from many disorders and problems in their physiological variables.
\end{abstract}

Key words: Body weight, physiological variables, blood variables.

\section{Introduction}

The tremendous technological progress that led to the dependence of the individual on the machine in the modern era and in all different fields led to the lack of human movement. Thus, it causes the lack of its physical and physiological efficacy, which made him vulnerable to many diseases, as the muscles move by converting chemical energy into mechanical energy. This cooperation determines the efficiency of the physical movement and thus advances the level of performance

\section{Corresponding Author:}

\section{Ahmed Abdulameer Ahmed}

Asst. Prof., Dept. of Students Activities/University of Basra-Iraq whenever these changes are positive in order to achieve the process of physiological change and the response of the body's systems to the performance of pregnancy ${ }^{(1)}$.

The ideal body weight is a vital subject for the human being during the stages of his life and the development of his maturity. The physiology is concerned with studying the effect of the change in body weight in every part of it and its relationship to changes in the body's internal organs and organs. The degree of these changes is related to many factors including the level of physical activity of individual."Even if we worked to improve and develop a person's fitness level, whether athletic or nonathletic, so that each element of fitness was developed without working to measure and define the components of his body, and more specifically determining what a person carries from his fat mass, it must be a program 
that lacks accuracy scientific and that leads us to the optimal elements."(2)

The Problem: The physical measurements of the weight and proportion of the fatty component are considered a basic for building the individual. That is, physical and motor activity lead to maintaining weight. Thus, it constitutes a critical importance in reducing or reducing physical and health deterioration. All studies indicate that non-athletic people have increased their weight and increased their blood pressure and have increased fat percentage in the blood. While those who exercised have maintained their cholesterol level, pressure of blood and their average of weight too, especially in adulthood, as this stage is considered one of the important stages in which the rate of obesity increases. Hence, it affects some physiological variables in the body.

The significant of the Study: The importance of the study lies on knowing the physiological variables of obese and non-obese people and making comparisons between them to understand the positive effects of the ideal weight of individuals, which is reached through the practice of physical activity and constantly on the physiological variables and work to develop and improve these variables in a way that serves the health aspect.

The aims of the Study: Identify the values of some physiological variables and compare these variables between obese and non-obese people.

The Procedure: The researchers used the descriptive method in the survey method. It is the best method to facilitate the achievement of the study aims. The descriptive approach is "an accurate visualization of the interrelationships between society, attitudes, tendencies, desires and development. The research gives an image of real life, setting indicators, and building future predictions."(3). "The aim of selecting the sample is to obtain information about a given society. As for the study population, it is the group through which researchers wish to generalize the results of its study"(4). The sample of study was chosen in the intentional way. It was represented by the third stage students of the Faculty of Physical Education at the University of Basra, where the sample size reached (30) participants from the students of the College of Physical Education and Sports
Science. The sample was divided into two groups and the size of each group was (15) participants after excluding the students sample of exploratory experience whose number was (5). The researchers used multiple tools as means by which they can reach the required data.

\section{The devices used to make the measurements are:}

1. An electronic medical scale for measuring the German made weight to the nearest (50 g).

2. A tape to measure the length.

3. Medical syringes to draw blood (40) syringes and sterile materials.

4. Plan tube

5. Cool box

6. Computer type (Pentium IIII) Korean made.

This procedure is consistent with most studies and research conducted in the same field which was "under the conditions of the sample abstaining from food at least 12 hours before drawing blood"(5). The blood drawing process was performed in the laboratory of Al-Jumhori General Hospital in Basra city, where the amount of blood withdrawal from each individual of the sample (five cc). The measurements that the researchers measured are (hemoglobin, blood sugar, and York acid, and blood viscosity, number of heart beats, number of breaths, systolic blood pressure, diastolic blood pressure).Before conducting the above measurements, the researchers conducted a survey experiment on Monday 12/03/2018 on a group of five female students and they were excluded from the main measurements of the study."The exploratory experiment is a scientific training for the researcher to determine the positives and negatives that occur during the test procedure to avoid them."'(6)

In order to achieve homogeneity among the individuals of the sample for each of the two research groups (obese and non-infected), the Law of Coefficient of Twist was used as their grades were limited to $(+3)$, which indicates the good distribution of the sample and its homogeneity in the study. This indicates the good distribution and homogeneity of the sample in the research. The statistical program (spss) version 22 was used by researchers to treat the results statistically. 
Displaying and analyzing the results of some physiological variables for students with obesity and nonobesity:

Table (1): Shows arithmetic mean, the standard deviation, the calculated, tabulated values (T) and the statistical result of blood variables tests for students with obesity and non-obesity.

\begin{tabular}{|c|c|c|c|c|c|c|c|}
\hline \multirow{2}{*}{ Tests } & \multicolumn{3}{|c|}{ Not obese } & \multicolumn{3}{|c|}{ Obese } & \multirow{2}{*}{ Result } \\
\hline & $\mathbf{A M}$ & SD & $\mathbf{A M}$ & SD & Calculated V & Tabled V & \\
\hline Hemoglobin & 11.23 & 0.55 & 10.11 & 0.26 & 4.126 & 2.88 & Moral \\
\hline SU & 85.6 & 6.21 & 98.5 & 5.8 & 5.612 & 2.88 & Moral \\
\hline S.Uric acid & 6.19 & 1.42 & 9.98 & 2.99 & 4.826 & 2.88 & Moral \\
\hline Blood viscosity & 31.8 & 1.32 & 35.1 & 2.14 & 5.81 & 2.88 & Moral \\
\hline
\end{tabular}

Table (1) includes the presentation of some of the results obtained by the researchers through measurements of the indicators of blood variables under study. It analyzes these results and discuss them after conducting statistical treatments for them. Through the results that the researchers reached to find out the significance of the differences for the hemoglobin variable, significant difference between female students without obesity and obesity in the variable (hemoglobin). Thus, it affects the daily activity of persons. Low levels of hemocycline that transport oxygen to working muscles affect air performance, which leads to a build-up of lactic acid and an inability to continue functioning (muscle fatigue) ${ }^{(7)}$.

The amount of hemoglobin in blood is more for boys and adults than for girls"(8).From the foregoing we conclude that there is an inverse correlation relationship between the increase in the percentage of fats (obesity) and the percentage of hemoglobin, since most times the increase in obesity is offset by a

decrease in blood hemoglobin levels, refers to significant difference between female students without obesity and obese women in the variable (blood sugar). For the benefit of students who are not infected and attribute, researchers are given the reason for this increase as a result of a decrease in the number of insulin receptors on the surface of cells or because of an imbalance in its shape as a result of increasing the lipid mass and fat percentage of students with obesity. Thus, sugar cannot enter cells, which leads to an increase in the percentage of blood in it. The level of blood sugar is also related to the effort made by the individual, where we notice a drop in the blood sugar level as a result of the effort exerted and that this effort requires energy to continue the muscular performance and the player's ability to withstand and increase the level of performance. ${ }^{(9)}$
The most important blood properties is to keep the

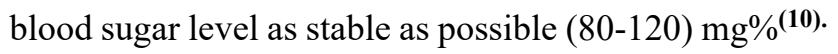
Through the foregoing, we conclude that people who enjoy a healthy and healthy body have the advantage of maintaining the blood sugar level within its natural limits for the large number of movement and daily activity that they do unlike obese people in which for the variable S. Uric acid, we find a significant difference between female students without obesity and those with obesity in the variable. For the benefit of other students, the women attribute the reason for this increase in the percentage of (S.ric acid) in the blood of female students with obesity and the normal rate due to the unhealthy diet followed by obese women, which was a major reason for increasing their weight. It contains a lot of meat and $\mathrm{fat}^{(11)}$. As one of the reasons for the high level (S. Uric acid) is eating meat in large quantities. As well as, the exercise of sports activities have a role in reducing levels (S. Uric acid) by stimulating blood circulation work to regulate the percentage of salts in the body and work to get rid of excess salts by putting them out by way of recognition. This is confirmed by Bahaa El Din Salama that increased activity of hormones, enzymes, and energy materials that participate in the metabolism process. ${ }^{(\mathbf{1 2}) \text {. }}$

we find the indicates that there is a significant difference between female students without obesity and those with obesity in the variable and for the benefit of students who are not infected and researchers attribute the reason that the level of blood viscosity is related to the number of red blood cells in one cubic milliliter of blood. "The viscosity and density of the blood are related to the amount of red balls, hemoglobin and protein plasma components." (13). In the case of immobility and activity, the degree of blood viscosity increases, which hinders the ease of its flow into the blood vessels ${ }^{(\mathbf{1 4})}$. 
Table (2): Shows arithmetic mean, standard deviation, calculated (tab) value, tabulation, and statistical result for examinations of some physiological variables for female students with obesity and non-infected

\begin{tabular}{|c|c|c|c|c|c|c|c|}
\hline \multirow{2}{*}{ Tests } & \multicolumn{3}{|c|}{ Not obese } & \multicolumn{3}{|c|}{ Obese } & \multirow{2}{*}{ Result } \\
\hline & AM & SD & AM & SD & Calculated V & Tabled V & \\
\hline Heart rate count & 75.6 & 2.67 & 83.7 & 3.94 & 4.386 & 2.88 & Moral \\
\hline The range of breath & 24.7 & 5.86 & 26.5 & 6.85 & 3.154 & 2.88 & Moral \\
\hline Systolic blood pressure & 121.4 & 2.792 & 129.6 & 8.395 & 4.628 & 2.88 & Moral \\
\hline Diastolic blood pressure & 80.7 & 2.195 & 85.5 & 2.22 & 10.382 & 2.88 & Moral \\
\hline
\end{tabular}

As for Table No. (2), it presents some of the results that the researchers reached through measurements of some physiological variables under study. Through it, we find that the number of heartbeats significant difference between students without obesity and those with obesity in the variable for the benefit of other students injured. The researchers attribute the reason to the lack of physical activity and the inactivity of female students with obesity. Moreover the lack of activity works to increase the heart rate because the heart muscle needs greater effort, constriction and extroversion, and then it increases Fatigue of the $\operatorname{arteries}^{(\mathbf{1 5})}$.

We find significant difference between female students without obesity and obese women in the variable and for the benefit of female students Non-infected. There searchers attribute the reason to the lack of fat for students without obesity, which leads to maintaining the average number of breathing times within normal limits, unlike female students with obesity. (Al-Hamoud et al., 2002) notes that "the breathing rate represents the number of breathing times and for athletes.

The rate is lower because training works to enhance the efficiency of the breathing process, as the athlete needs a smaller number of breaths to transport the same volume of air."Having a look on the variable systolic blood pressure rate, we find significant difference between female students without obesity and those with obesity in the variable and in favor of Female students who are not infected. To overcome this pregnancy, the heart muscle compensates for this by increasing the volume. "Nayef Magdy and Sobhi Ahmed" stress that "exercising regularly and eating low-cholesterol and fat food makes blood pressure natural in some cases, so there is no need to take medicines or their amounts can be reduced."
Goldberg (1988) indicates that using the appropriate aerobic training method, following the conditions for feeding and controlling other healthy habits leads to a systolic blood pressure drop of $10 \mathrm{~mm} \mathrm{Hg}$ from the mean ${ }^{(16)}$.

As for blood pressure, we find a significant difference between female students without obesity and those with obesity in the variable and for the benefit of other students women suffer from. the researchers attribute the reason to the fact that female students without obesity are more active and active than the affected female students. "That sports activity affects in two ways the first is improving the level of physical fitness and the second is helping to strengthen the heart muscle itself. Therefore, we notice in individuals who exercise sports regularly low heart rate. There is a decrease in the blood pressure rate by comparing them with idle individuals with little movement because the people who are more mobile have flexibility in the arteries. This helps in maintaining its elasticity at the same time, maintaining the economical work of the heart ${ }^{(17)}$. The injured and those who suffer from many disorders and problems in their physiological variables in general and blood variables in particular, which may be the beginning of many diseases related to obesity.

Ethical Clearance: The Research Ethical Committee at scientific research by ethical approval of both environmental and health and higher education and scientific research ministries in Iraq

Conflict of Interest: The authors declare that they have no conflict of interest.

Funding: Self-funding 


\section{References}

1. Majeed Musleh, Raisan Khoreibet, and Ali Turki. Physiology of Sport, Dar Al-Fikr Al-Arabi, Egypt, (2002). p. 19.

2. Nawal Mudhar Ahmad Rafeeq Al-Jumaili.: "The effect of lowering the lipid component on fitness elements". Experimental Study on Women Who Have a Higher fat Percentage than the Ideal Limit. Unpublished Master Thesis, University of Baghdad. (1994)P. 2.

3. Wajih Mahjoub..Scientific Research and Method, Baghdad, Dar Al-Kutub for Printing and Publishing, (2002) p. 267.

4. Ahmad Al-Khatib..Scientific Research and Higher Education, 1st ed., Jordan - Amman, Al Masirah House for Publishing and Distribution, (2003) p. 43.

5. Davis . C. Etal.. The Effect Moderate Physical Exercise on the Plasma HDL Lipoprotein Levels with other Plasma Lipid with other Plasma Lipid and Lipoprotein Concentration .(1980) 62 p . 25.

6. Qasim Hassan Al-Mandlawiet al..Training Bases for Athletics Events, Baghdad, Higher Education Press, (1990) p. 107.

7. Kimberly j. Mueller, M.S..When Fatigue Slows you down: Iron-deficiency Anemia, Active. Com. (2006) April. 10.

8. Omaima Hamed Abu Al-Khair, Hamed Ahmed Al-Haftawi. "The Effect of a Proposed Natural Nutritional Complex on the Skilled Physical Effort in Volleyball Competitions", Alexandria, Scientific Journal of Physical Education, Fifth Issue, (1988). p. 167.
9. Abul-Ela Ahmad Abdel-Fattah. (2003). References Series in Physical Education and Sports Physiology of Training and Sports, Cairo, Dar Al-Fikr AlArabi, P. 89

10. Muhammad Ramzi Al-Omari. Clinical Chemistry, Technical Institutes Authority Press, Baghdad, (1986). 3: p. 90.

11. Bahaa El-Din Ibrahim Salama. Biology of Sports and Motor Performance: (Growth and Development, Athletic Training, Energy and Nutrition, Hormones, Stimulants), 1st edition. Cairo, Dar Al-Fikr Al-Arabi, (1992).p. 45.

12. Bahaa El-Din Ibrahim Salama. Biochemical Properties of Mathematical Physiology, Cairo: Dar Al-Fikr Al-Arabi, (2008). pp. 234-235.

13. Hazem Al-Nahar et al. Sports and Health in Our Lives, 1st ed, Al-Yazouri Publishing and Distribution House, Amman, (2010). p. 227.

14. Muhammad Hassan al-Hammoudet al. Human Biology: Digestion, Circulation, Respiration, Neurotransmission. 2nd edition, Amman, Al-Ahlia Publishing and Distribution, (2002) p. 45.

15. Nayef Mofdi and Sobhi Ahmed. Sport is Health, Agility and Flexibility, 1st edition, Arab Society Library for Publishing and Distribution, Amman, (2012). p. 65.

16. Larry, .G .S .Essential of Exercise Physiology, Burgess pubishiry company . (1081). .p 106.

17. Journal of Sports Medicine Sciences, Scientific Periodical Journal, No. 2, Bahrain, 1995, p. 33. 